Villar Navascués, Rubén. Las viviendas subterráneas y el riesgo sísmico. GeoGraphos [En línea]. Alicante: Grupo Interdisciplinario de Estudios Críticos y de América Latina (GIECRYAL) de la Universidad de Alicante, 2 de julio de 2016, vol. 7, no 88, p. 147-170. [ISSN: 2173-1276] [DL: A 371-2013] [DOI: 10.14198/GEOGRA2016.7.88].

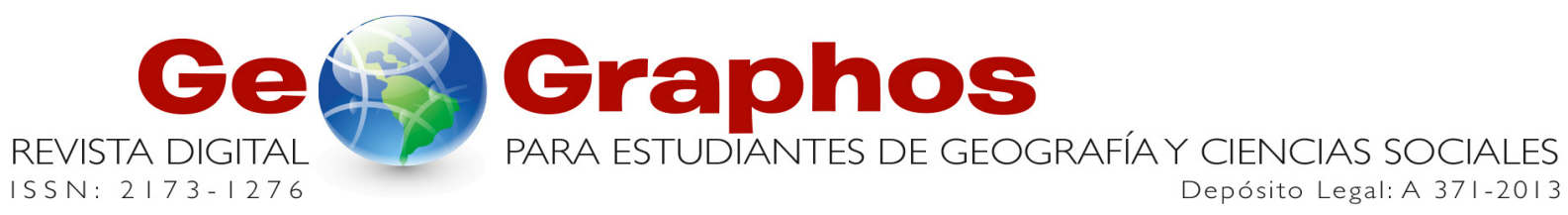

$<\underline{\text { http://web.ua.es/revista-geographos-giecryal }>}$

Vol. 7. $\mathrm{N}^{\mathrm{o}} 88$

Año 2016

\title{
LAS VIVIENDAS SUBTERRÁNEAS Y EL RIESGO SÍSMICO
}

\author{
Rubén Villar Navascués \\ Doctorando en Geografía \\ Instituto Interuniversitario de Geografía. Universidad de Alicante \\ (Alicante, Comunidad Valenciana, España) \\ Correo electrónico: rvnavascues@ gmail.com
}

Recibido: 26 de junio de 2015. Devuelto para revisión: 17 de julio de 2015

Aceptado: 2 de julio de 2016

\section{RESUMEN}

Se estima que las viviendas subterráneas a lo largo del mundo albergan entre 40 y 60 millones de personas. Tras un análisis general de las tipologías de viviendas subterráneas, de su localización y de los factores que influyen en su desarrollo se ha introducido el análisis de la vulnerabilidad de este tipo de viviendas ante los riesgos naturales, cuestión que no ha sido estudiada exhaustivamente con anterioridad. Cabe destacar que la localización de las viviendas subterráneas a lo largo del mundo coincide en la mayor parte de los casos con regiones activas sísmicamente, por lo que se lleva a cabo una primera aproximación al estudio de la vulnerabilidad de las viviendas subterráneas frente al riesgo sísmico, teniendo como antecedente el terremoto de la región china de Shaanxi ocurrido en 1556, que afectó a grandes agrupaciones de viviendas subterráneas. 
Palabras clave: Vivienda subterránea, vivienda bioclimática, riesgo sísmico, patrimonio histórico, terremoto de Shaanxi.

\title{
UNDERGROUND DWELLINGS AND SEISMIC RISK
}

\begin{abstract}
It is estimated that underground dwellings throughout the world are home to between 40 and 60 million people. After a general analysis of the types of underground dwellings, their location and the factors influencing its development, analysis of the vulnerability of this type of housing has been introduced against natural risks, issue that has not been thoroughly studied before. It should be noted that the location of underground dwellings throughout the world matches in most cases with active regions seismically, so a first approach is carried out to the study of the vulnerability of underground dwellings compared to the seismic risk, having as background the earthquake in the Chinese region of Shaanxi occurred in 1556 that affect large groups of underground dwellings.
\end{abstract}

Key words: Underground Dwellings, Housing Bioclimatic, Seismic Risk, Historical Heritage, Shaanxi Earthquake.

\section{AS MORADIAS SUBTERRÂNEAS E RISCO SÍSMICO}

\section{RESUMO}

Estima-se que as moradias subterrâneas ao longo do mundo albergam entre 40 e 60 milhões de pessoas. Depois de uma análise geral das tipologías de moradias subterrâneas, de sua localização e dos factores que influem em seu desenvolvimento, se introduziu a análise da vulnerabilidade deste tipo de moradias ante os riscos naturais, questão que não tem sido estudada exaustivamente anteriormente. Cabe destacar que a localização das moradias subterrâneas ao longo do mundo coincide na maior parte dos casos com regiões ativas sismicamente, pelo que se leva a cabo uma primeira aproximação ao estudo da vulnerabilidade das moradias subterrâneas em frente ao risco sísmico, tendo como antecedente o terremoto da região chinesa de Shaanxi ocorrido em 1556 que afetou a grandes agrupamentos de moradias subterrâneas.

Palavras chave: Moradias subterrâneas, habitação bioclimática, risco sísmico, patrimônio histórico, terremoto de Shaanxi.

\section{INTRODUCCIÓN}

Las viviendas subterráneas, conocidas también como casas-cueva, cuevas artificiales o vivienda troglodita, entre otros sinónimos, han dado cobijo y protegido al ser humano desde hace muchos siglos, evolucionando en sus variedades y tipologías y perdurando hasta la actualidad. Estas viviendas forman parte de la arquitectura popular, entendida como una manifestación artística de un determinado grupo social, donde destaca el carácter racional y sencillo de su construcción, que sigue criterios funcionales, mostrando una perfecta adaptación de la vivienda al medio geográfico y a unas determinadas necesidades sociales. Un rasgo que define a esta arquitectura es la lentitud en sus variaciones, ya que son viviendas autoconstruidas fruto de una creación colectiva basada en un proceso de prueba y error que ha 
sido trasmitido, y en su caso corregido y adaptado si era necesario. Esta vivienda se inserta en el medio rural normalmente, situadas al margen del mercado de la vivienda hasta hace un par de décadas, ya que, históricamente, se ocupaban por jornaleros agrícolas empobrecidos.

La necesidad en el presente de propuestas arquitectónicas bioclimáticas que acentúen la eficiencia energética y la búsqueda de modelos urbanos sostenibles y ecológicos están provocando un cambio de actitud en la consideración de estas viviendas como alternativa urbanística. Esto es así porque, además de aprovechar la inercia térmica del terreno para ahorrar energía, se pone en valor el patrimonio cultural y paisajístico del territorio, entendido como el resultado de las interacciones de los elementos naturales y sociales a lo largo de la historia. Pero de momento estos estudios se centran más en cuestiones arquitectónicas que territoriales, obviando las repercusiones que los riesgos naturales puedan provocar en este tipo de viviendas. La existencia de varios episodios históricos en los que un desastre natural ha provocado un gran número de muertes, así como graves daños estructurales, motiva el estudio de las interacciones entre los riesgos naturales y las viviendas subterráneas ya que se estiman que dan cobijo en todo el mundo a una cifra que oscila entre los 40 y los 60 millones de personas (Piedecausa, 2012). A pesar de esta cifra, la importancia del trogloditismo, referido al fenómeno de hábitat subterráneo, se ha reducido con el paso del tiempo alrededor del mundo, aunque en algunas regiones ha pervivido con mayor profusión. Una de estas regiones es la mediterránea, y en concreto el sureste de la Península Ibérica, donde la gran extensión de este tipo de hábitat, aunque en franca recesión desde hace décadas, enfatiza la necesidad de un conocimiento más detallado de las interacciones entre riesgos naturales y hábitat troglodita, más aun si tenemos en cuenta las características sísmicas de esta región geográfica.

Para presentar el tema se abordarán primero ciertas cuestiones generales en cuanto a las características territoriales de las viviendas subterráneas, referidas a su distribución y origen, factores que influyen en su localización y finalmente, los factores que influyen en un aumento de su vulnerabilidad ante determinados riesgos naturales, poniendo énfasis en los riesgos sísmicos y en un episodio histórico que afectó brutalmente a grandes agrupaciones de hábitat troglodita en la China a finales del siglo XVI.

\section{LOCALIZACIÓN DE LAS CASAS-CUEVA}

Al buscar los orígenes de este tipo de hábitat no encontramos una fecha concreta ni un área geográfica particular, puesto que la distribución de las cuevas, como veremos, es bastante amplia. Se olvida que antes del establecimiento de las primeras civilizaciones en Oriente Medio las cuevas y, presumiblemente, las construcciones subterráneas habían sido quienes habían acogido al hombre durante su evolución. De hecho algunos autores indican que es posible hallar indicios de estructuras sorprendentes incluso con 1,6 millones de años (Omedes y Piqué, 2003). Para hacer una aproximación a la distribución actual del hábitat subterráneo alrededor del mundo hay que basarse en los trabajos realizados en los años cincuenta por Jessen, ya que no se encuentran investigaciones más actuales que permitan clarificar el gran descenso en la ocupación de estas viviendas durante la segunda mitad del siglo XX, especialmente en el Mediterráneo (Urdiales, 1987).

Si se observa la distribución mundial de la vivienda subterránea (Figura 1), se comprueba cómo su ubicación se centra principalmente a lo largo del paralelo $40^{\circ}$ norte, ya que se relaciona con factores climáticos. Según Deffontaines (1980, p.23): 
“(...)parecen estar ubicadas sobre todo en las zonas de clima cálido y caluroso, allí donde la vegetación es escasa, con bosques casi ausentes, pero igualmente en las regiones con cambios bruscos de temperatura donde protegen tanto del exceso de calor y de luz como de los fuertes vientos y el frío extremo".

Figura 1. Localización de vivienda subterránea a nivel mundial

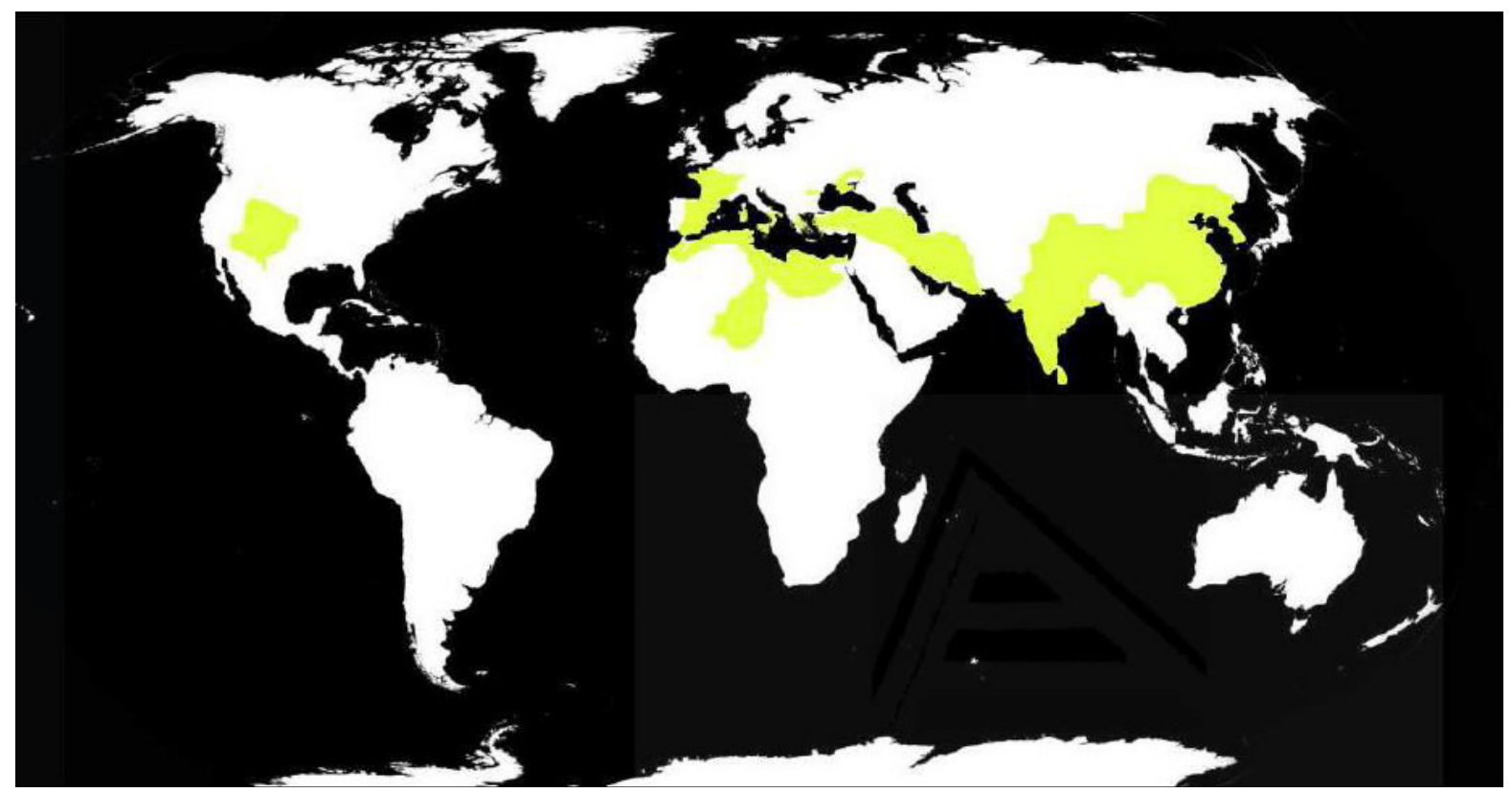

Fuente: Piedecausa, 2012, p. 57.

Además, encontramos una característica común en el análisis de la distribución de casascueva a lo largo del mundo, y es que han sido utilizadas por las tribus indígenas en todos los continentes. Este hecho es más apreciable en continentes que, como América y Oceanía, han sido colonizados por europeos relativamente hace poco tiempo, lo que supuso el fin de la utilización de este tipo de hábitat. También podemos apreciar que el establecimiento de las casas-cueva se da sobre diferentes topografías y litologías, ya que las encontramos, por ejemplo, sobre materiales volcánicos en Turquía o arcillosos en las mesetas de Irán e Iraq, y más hacia el este, llegamos a encontrar cuevas construidas sobre materiales loésicos en China. Localizamos este hábitat en todos los continentes, aunque es bastante común que se asocie la vivienda en cuevas a la cuenca mediterránea, pues prácticamente se ha extendido por todos los países a los que baña este mar y es en torno a él donde más se han desarrollado (Figura 2).

Esto puede deberse a que la vivienda subterránea tenga su origen en África, ya que el Magreb es la región donde ha habido una producción más abundante de este tipo de viviendas. La importancia que el hábitat subterráneo ha tenido en esta región ha sido tal, que S. Gsell (1913: 297) llega a afirmar que:

“(...) el propio nombre de África, Ifrika, provendría de ese tipo de viviendas; en berebere, las cueva se llaman "ifri" o "afri" y los Romanos habrían bautizado como Africanos a estas gentes de las cuevas". 
Jessen (1955), por otro lado, destaca la tradición troglodítica del Asia mediterránea (Israel, Palestina, Siria, Jordania y Turquía) remarcando la densidad y diversidad de este hábitat en la meseta de Anatolia, que presenta unas características naturales muy proclives al establecimiento de este tipo de vivienda, ya que es una región donde coexisten grandes amplitudes térmicas y bajas precipitaciones. Según Leo Diáconus, escritor bizantino del siglo $\mathrm{X}$, la región turca de Capadocia era la "terra troglodítica", manteniéndose en la actualidad muchos de esos antiguos asentamientos e incluso algunos nuevos. Por último, hay que destacar como otro de los centros importantes del trogloditismo mediterráneo el sureste de la Península Ibérica, cuyo origen y distribución se analizará posteriormente.

Figura 2. Ubicación de vivienda subterránea a lo largo de todo el Mediterráneo

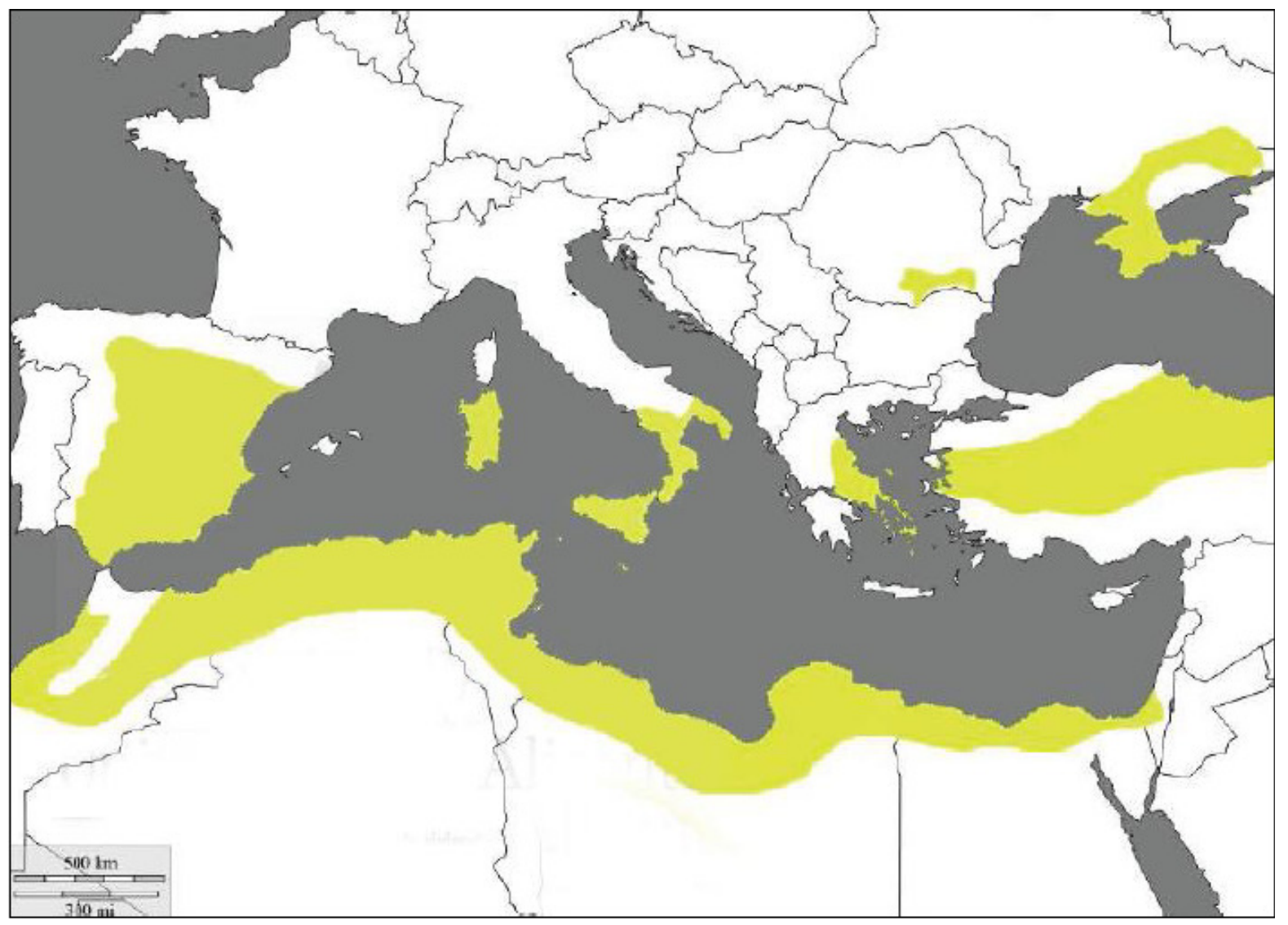

Fuente: Piedecausa, 2012, p. 58.

\section{TIPOLOGÍAS DE VIVIENDA SUBTERRÁNEA}

Como hemos visto, la distribución del hábitat subterráneo es muy amplia. Dentro del concepto de hábitat subterráneo se agrupan diferentes tipologías de vivienda que varían en función del área geográfica donde se localizan, ya que encontramos distintos contextos naturales y socioeconómicos que influyen en la construcción de estas viviendas. Las tipologías de vivienda subterránea, por tanto, han ido variando a lo largo del espacio y del tiempo, siendo las siguientes sus principales variedades: 


\section{Tipología de vivienda subterránea horizontal}

Se trata de un tipo de vivienda subterránea excavada en la horizontal, a una sola altura. Se suelen disponer, por tanto, sobre laderas y habitualmente se encuentran dispuestas unas sobre otras formando hileras de viviendas (Figura 3). Este tipo de vivienda subterránea es la más habitual en la Península Ibérica, y de manera general en todo el mundo. Además, esta tipología ofrece un buen aislamiento térmico y permite una organización funcional del espacio en que se encuentra al establecerse relaciones entre los distintos niveles estanciales.

Figura 3. Cueva escalonada en ladera.

Sección vertical de cueva en Almanzora

(Almería, España)

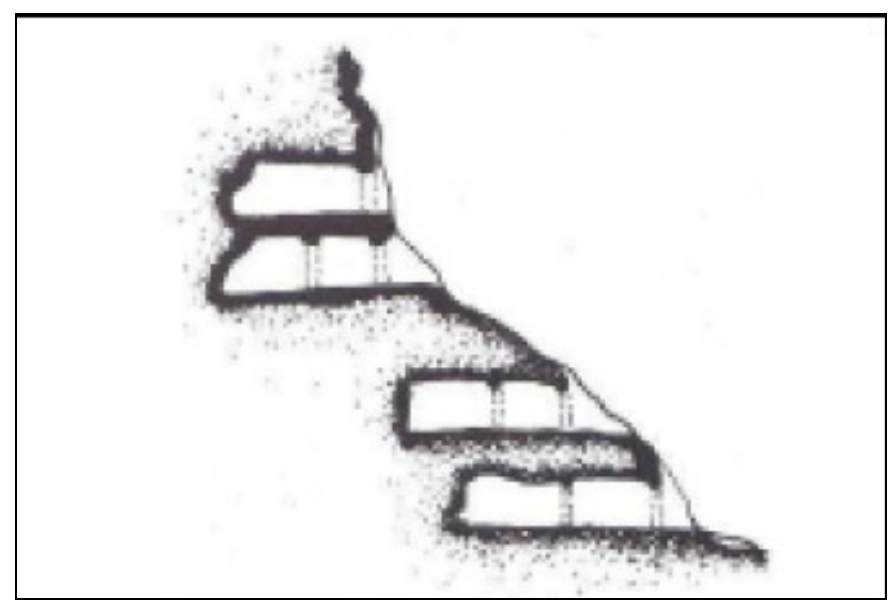

Fuente: Piedecausa, 2012, a partir de Neila, 2004, p. 403.

\section{Tipología de vivienda subterránea vertical}

Esta tipología proviene del norte de China, donde predominan los terrenos de loess, ya que desde el Neolítico se ha desarrollado formando las viviendas excavadas en forma de "saco" (Figura 4). Este tipo de cuevas suponían hábitats muy rudimentarios y presentaban problemas de excavación y de protección frente al viento, el agua y el sol. Posteriormente evolucionaron en las actuales yaodangs de tipología mixta. 
Figura 4. Sección vertical de la vivienda del Neolítico excavada en "saco".

Pueblo de Jing. Provincia de Shanxi. China.

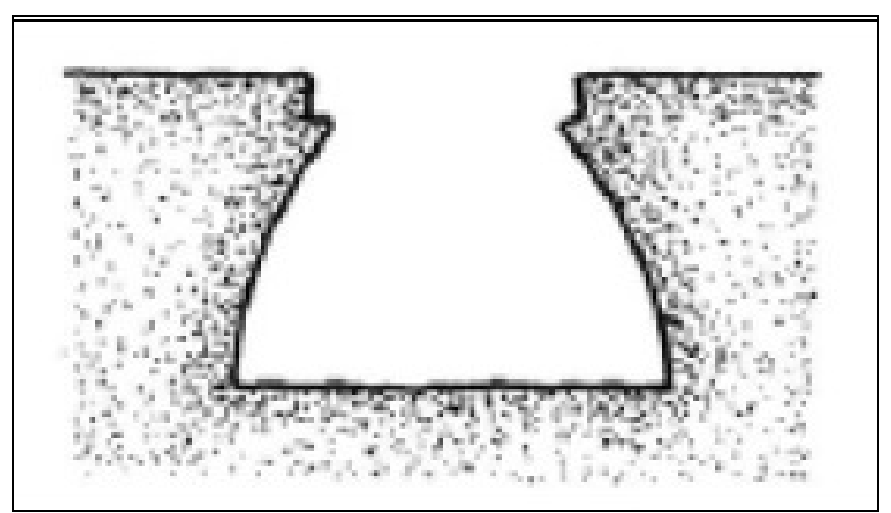

Fuente: Piedecausa, 2012, a partir de Loubes, 1985, p. 20

Excavación en formaciones singulares: arquitectura sustractiva en superficie.

Este tipo de viviendas subterráneas se encuentran construidas sobre toba volcánica en la región de Capadocia (Turquía). Esta tipología aprovecha topografías que forman edificios verticales para excavarlas y aprovechar así las ventajas estratégicas de una posición elevada (Fotografía 1).

Fotografía 1. Vista general de las viviendas construidas sobre edificios verticales de toba volcánica en la región de Capadocia (Turquía)

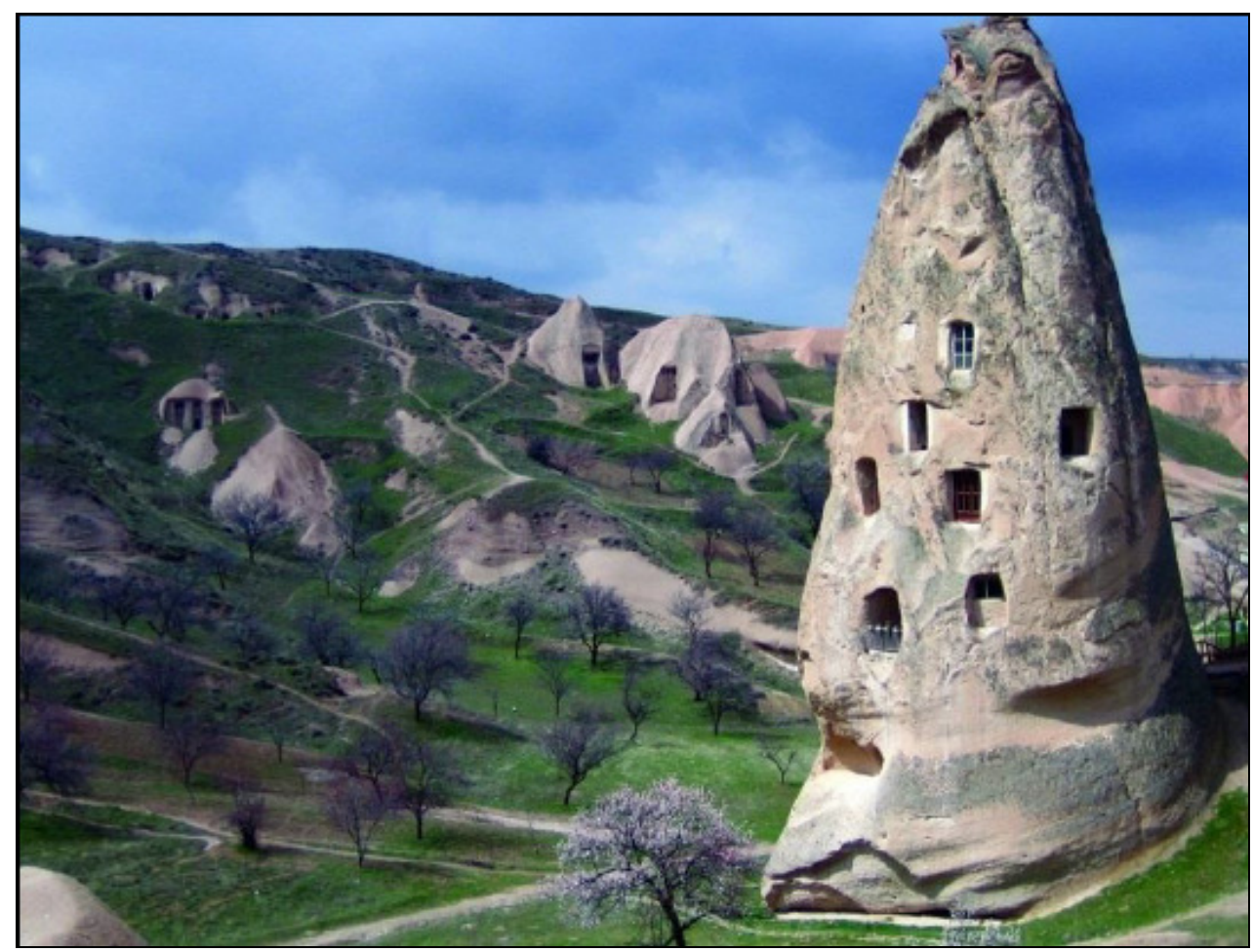

Fuente: <http://thewow.com.mx/wp-content/uploads/2013/04/bajolatierra20.jpg >. 


\section{Excavación horizontal y vertical. Arquitectura mixta.}

En lugares sin elementos montañosos o pendientes acusadas se ha desarrollado una tipología que mezcla la excavación vertical y la horizontal. Este sistema comienza abriendo un patio en vertical para generar un plano horizontal más profundo, y a partir de él excavar horizontalmente las habitaciones en disposición radial a partir de este vacío (Fotografía 2).

Esta tipología ha generado gran diversidad de formas y agrupaciones en diferentes climas y continentes, tales como las casas-cueva de Matmata (Túnez) o los yaodangs del norte de China. Entre las ventajas que ofrecen se encuentran una buena protección contra el viento, incluyendo en el caso de Matmata las tormentas de arena; una mejor iluminación y un microclima gracias al patio excavado que hace soportable los extremos térmicos y la ventaja de pasar desapercibidas en el paisaje, camuflándose así de posibles enemigos.

\section{Fotografía 2. Excavaciones en cráteres subterráneos de Matmata (Túnez)}

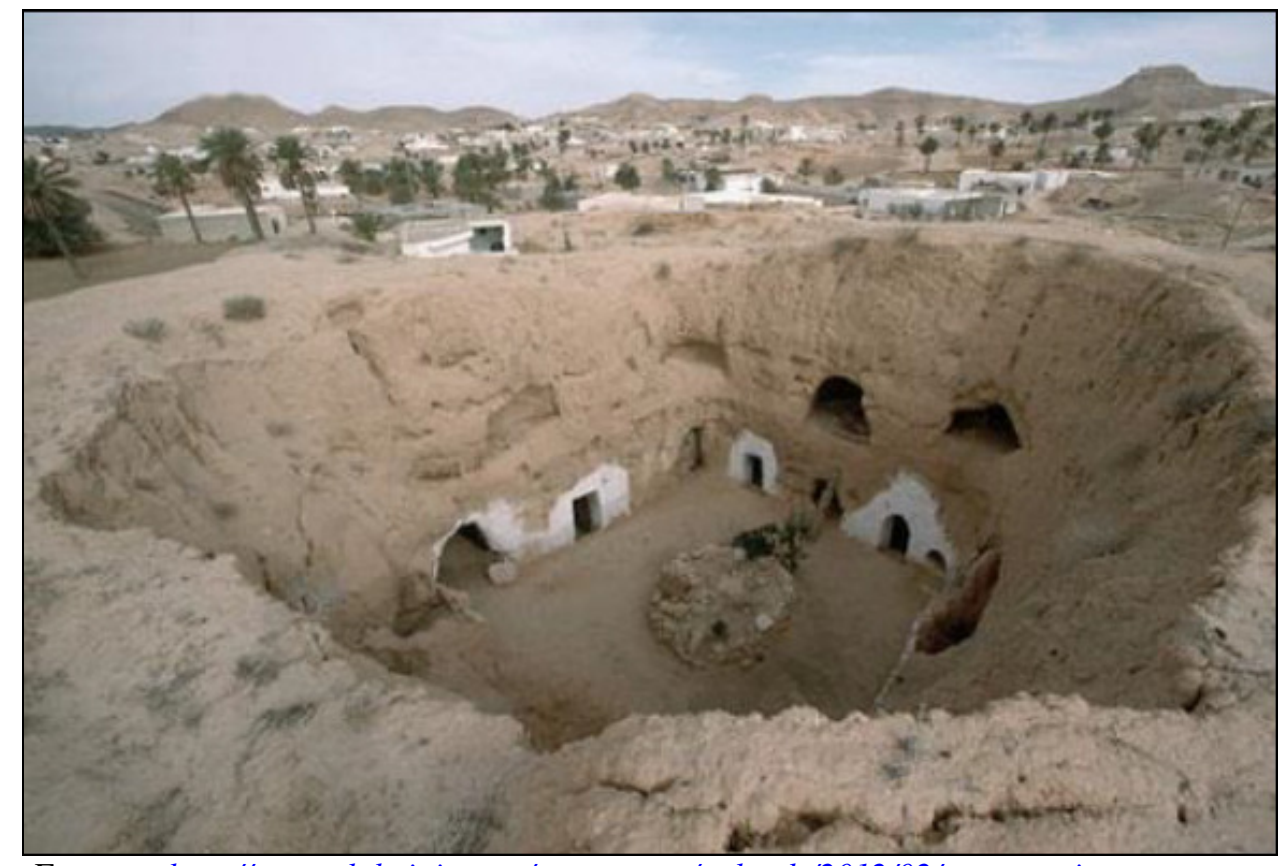

Fuente: <http://www.clubviaje.com/wp-content/uploads/2012/02/matmata.jpg >.

\section{FACTORES EXPLICATIVOS DEL ORIGEN DE LAS VIVIENDAS SUBTERRÁNEAS}

Según Gonzalo (2003), desde una aproximación general son dos los grupos de factores que han influido en la evolución de la vivienda subterránea. Por una parte tenemos las características físicas del terreno (topografía, clima y litología), que son determinantes a la hora de posibilitar la excavación de una vivienda subterránea, y también en su estabilidad y duración.

El segundo grupo de factores lo constituyen los socioculturales, relacionados básicamente con la estructura social y productiva de cada sociedad. En función de ambos grupos de factores se establece el origen de cada asentamiento troglodita, que surge como una adaptación a la combinación de esas condiciones dadas, naturales y sociales, por lo que suele ser diferente para cada región. De este abanico de factores aparecen las distintas tipologías analizadas en el 
apartado anterior. En definitiva, la cueva supone una forma de hábitat perfectamente adaptada al área geográfica, e históricamente es el resultado de la conjunción de un medio físico determinado y de una población con unas necesidades específicas que la llevan a ocupar el subsuelo como vivienda.

\section{Factores topográficos}

En algunas regiones, como la mediterránea, las cuevas se asientan preferentemente sobre laderas, como consecuencia de diversos factores. Uno de ellos es el riesgo de inundación al que se ven sometidos los llanos mediterráneos por las lluvias torrenciales características del clima en la región. Por ello las cuevas se localizan preferentemente sobre laderas, aprovechando para uso agrícola el suelo útil de los piedemontes y otras zonas marginales de las llanuras sin ocupar. Además, otro factor de primer orden en la localización de las casascueva sobre laderas es su orientación. En el hemisferio norte ésta es preferentemente sur, sudeste o sudoeste para favorecer la iluminación de la vivienda, aunque la orientación favorita suele ser la sudeste o sudoeste, lo que permite evitar una completa exposición a la radiación solar.

Pero en otras regiones se dan otro tipo de casas-cueva excavadas sobre topografías llanas, las de tipología mixta, construidas en la vertical y la horizontal.. El inconveniente en la construcción de casas-cueva sobre los fondos de valle tiene que ver con el nivel freático. Es un factor importante puesto que, como veremos, la humedad constituye uno de los principales factores de riesgo para la estabilidad de las casas-cueva.

\section{Factores climáticos}

Generalmente la vivienda se localiza en zona de clima árido o semiárido, con un bajo volumen de precipitaciones medias anuales, ya que la humedad es incompatible con la perdurabilidad de las viviendas subterráneas. Además, en este tipo de climas, de carácter extremo, se dan grandes amplitudes térmicas, para lo cual las cuevas constituyen una buena adaptación ya que aíslan muy bien de la temperatura exterior. Por todo esto, el hábitat subterráneo se presenta como una buena solución frente a los extremos de temperatura, ya que (...) "las viviendas subterráneas protegen tanto del exceso de calor como de los fuertes vientos y fríos excesivos" (Urdiales, 1987).

\section{Temperatura de la cueva}

La vivienda subterránea, se encuentra aislada de la temperatura exterior gracias a sus espesos muros, que además dan estabilidad a la construcción y aíslan acústicamente. La homeostasis térmica, término importado de la biología para referirse a la capacidad de mantener una condición interna estable a pesar de los cambios en el entorno, permite que la temperatura interior de las viviendas subterráneas se mantenga constante a lo largo del año sin que se experimenten grandes variaciones. Esto es así debido a que la temperatura diaria de la cueva disminuye con la profundidad tal y como muestra la figura 5. De esta manera se amortiguan las variaciones estacionales de temperatura a los cinco metros de profundidad, obteniendo una temperatura interior similar a la temperatura media anual del lugar concreto donde se instala la cueva. 
El subsuelo, por tanto, es isotérmico y esto permite asegurar una gran eficiencia energética, tan buscada para los actuales edificios de viviendas verticales, y es por esto por lo que la arquitectura moderna valora los beneficios económicos y ecológicos de este tipo de hábitat (Maccarone, 2009).

\section{Factores litológicos}

Existen una serie de condicionantes litológicos que favorecen y permiten la construcción de casas-cuevas sobre determinados materiales:

- Bases desmenuzables y fáciles de cortar: La construcción de cuevas se ha desarrollado normalmente sobre materiales fáciles de excavar. Esto se corresponde con depósitos de rocas sedimentarias blandas tales como los conglomerados, las areniscas o las margas. Los materiales demasiado frágiles son inapropiados por su facilidad de desmoronamiento, y las rocas muy duras también lo son por la dificultad de excavarlas.

\section{Figura 5. Variación de la temperatura del terreno a lo largo del año según la profundidad}

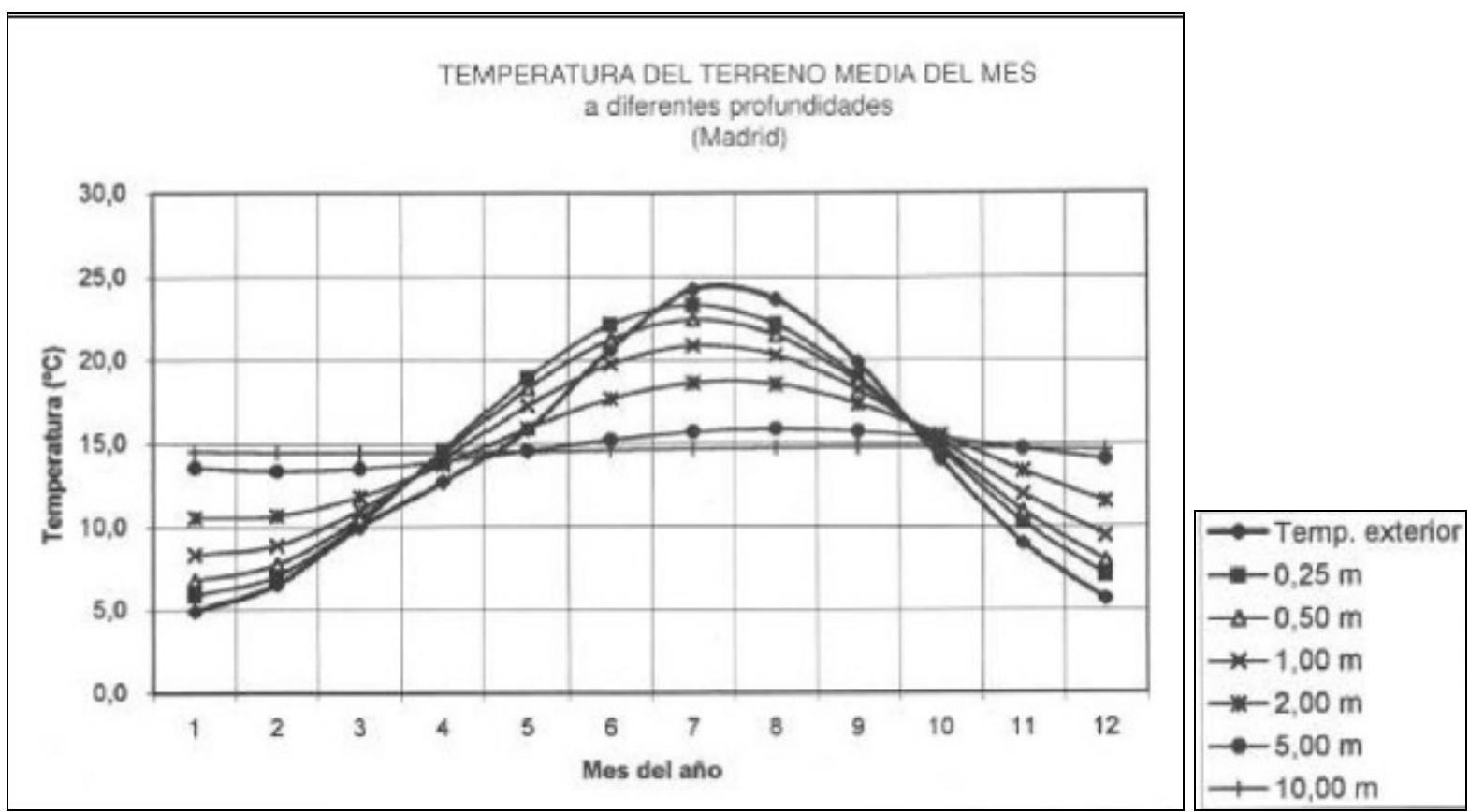

Fuente: Neila, 2004, p. 409.

- Gran capacidad impermeable: Mayoritariamente esta característica la cumplen los depósitos volcánicos o las rocas sedimentarias, siempre que se sitúen allí donde el nivel freático sea lo suficientemente profundo (Urdiales, 1987), ya que un exceso de humedad puede alterar la capacidad de retención hídrica del material.

- Con capacidad de cohesión: Los materiales más apropiados son aquellos que se encuentran compactados y cementados. En ocasiones las cuevas se construyen sobre materiales que, en principio, no cumplen este requisito como son la toba volcánica o el loess, pero estos materiales tienen la capacidad de endurecerse con el paso del tiempo y hacerse lo suficientemente compactos como para evitar derrumbamientos en la vivienda. 
- Sin humedad excesiva: Hay que tener en cuenta también la capacidad acuífera del material, ya que pueden aparecer goteras y afectar al grado de humedad de la vivienda, aspecto que constituye, como veremos, un factor de riesgo.

\section{Factores socioculturales}

Históricamente, las causas que han llevado a la población a buscar como refugio la vivienda subterránea se pueden agrupar en dos, según sus necesidades, constituyendo la ocupación del subsuelo una práctica de adaptación social.

\section{Adaptación defensiva}

Al igual que en el origen de otro tipo de asentamientos, la unión entre viviendas subterráneas se planteó con fines de defensa colectiva (Piedecausa, 2012), emplazándose generalmente estos núcleos en lugares con dificultad de acceso. Un ejemplo de estos asentamientos lo encontramos en las agrupaciones lineales o pueblos en acantilados, de tipología horizontal. Éstos se sitúan en laderas bien orientadas y resguardadas de los vientos dominantes con una pendiente casi vertical, que dificulta el acceso a ellos (Fotografía 3). Un caso paradigmático de este tipo de adaptación en la Península Ibérica lo constituye Cuevas de Almanzora (Almería), con hileras paralelas de viviendas en laderas de gran pendiente (Fotografía 4).

\section{Fotografía 3. Vista general de la denominada Square Tower House en Mesa Verde. Colorado, EE.UU.}

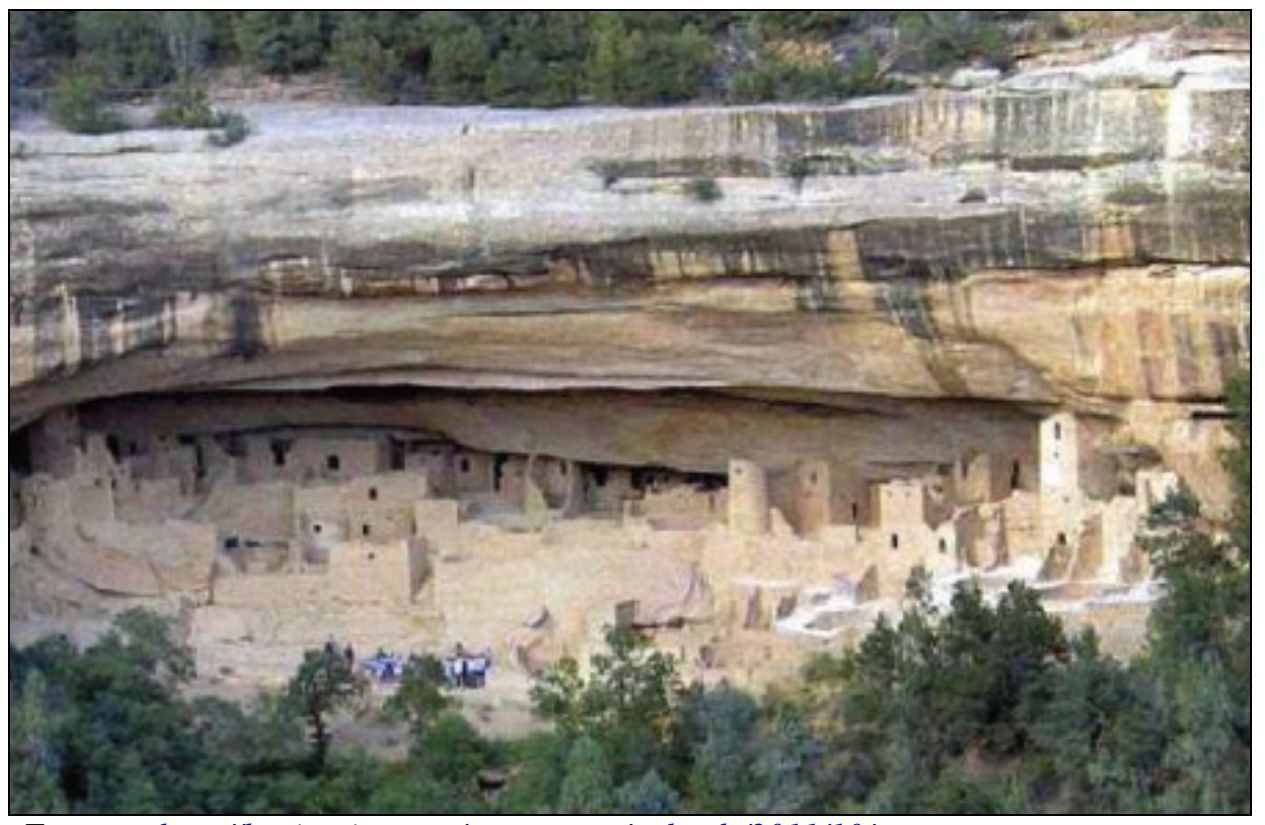

Fuente: <http://bacinerias.com/wp-content/uploads/2011/10/>. 


\section{Fotografía 4. Vista general de las casas-cueva en Cuevas de Almanzora}

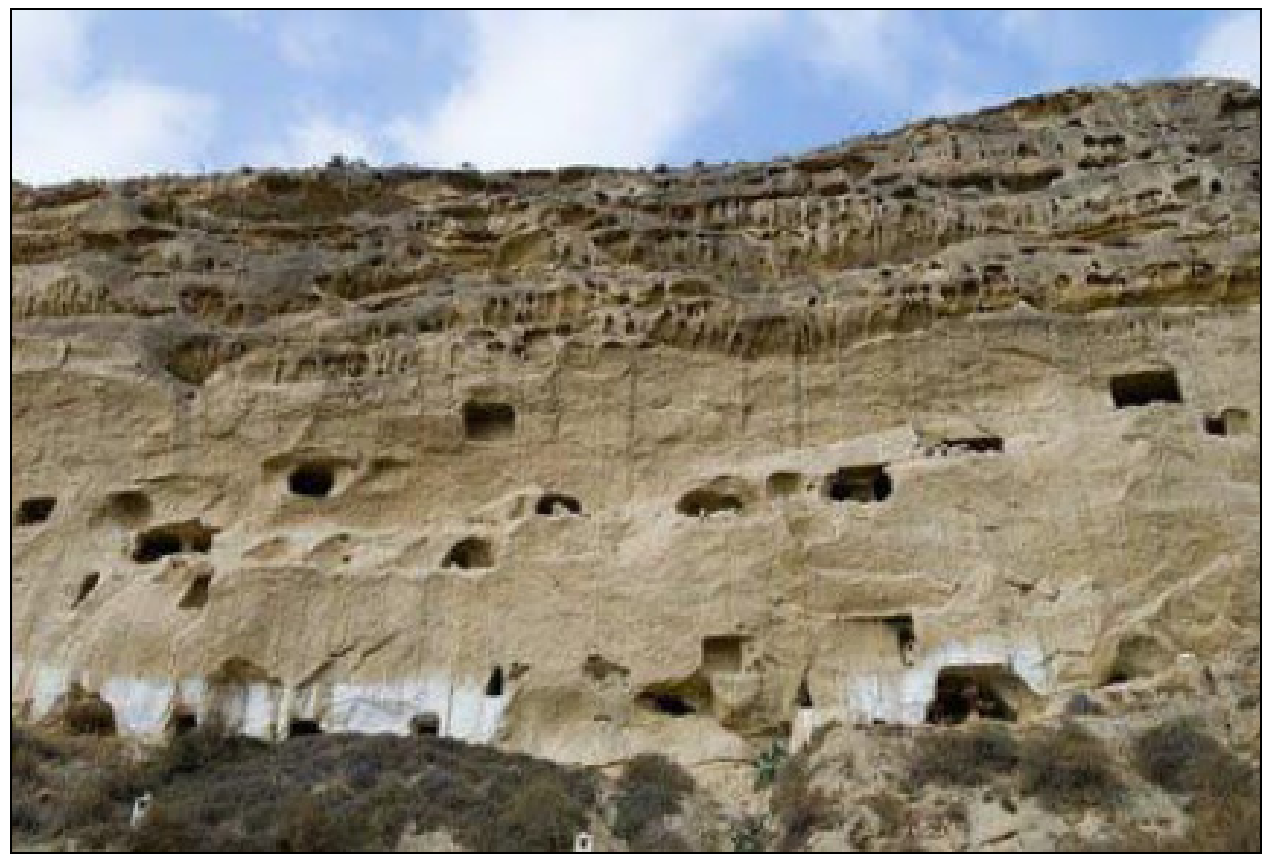

Fuente: <www.nps.gov/meve/historyculture/cd_cliff_palace.htm Cuevas-del-

Almanzora.jpg >

Otro tipo de adaptación defensiva la encontramos en las tipologías de cuevas excavadas sobre elementos rocosos superficiales como es el caso de los pueblos sobre conos en Capadocia (Turquía), donde se utilizan los montículos preexistentes como puntos estratégicos donde situar las viviendas, lo que permite vigilar y controlar el territorio. En esta misma región encontramos un caso especial de adaptación defensiva. Se trata de dos agrupaciones de excavación mixta (en la horizontal y en la vertical), Kaymakli y Derinkuyu, que llegan a formar auténticas ciudades bajo tierra que podían llegar a albergar unas 10.000 personas en diez niveles bajo el suelo, extendiéndose a través de varios kilómetros (Piedecausa, 2012).

El origen de estas agrupaciones data del siglo I. Su función era defender a la población, a modo de fortificación, frente a persecuciones políticas, religiosas o militares de pueblos vecinos (persas, macedonios, romanos, o los islámicos en el siglo VII). En caso de ataque se aislaba a la población dentro de las galerías obstruyendo las entradas. Esto era posible gracias a una compleja red de ventilación y una organización que permitía a sus pobladores permanecer largos períodos en el interior de la tierra (Figuras 6 y 7). 


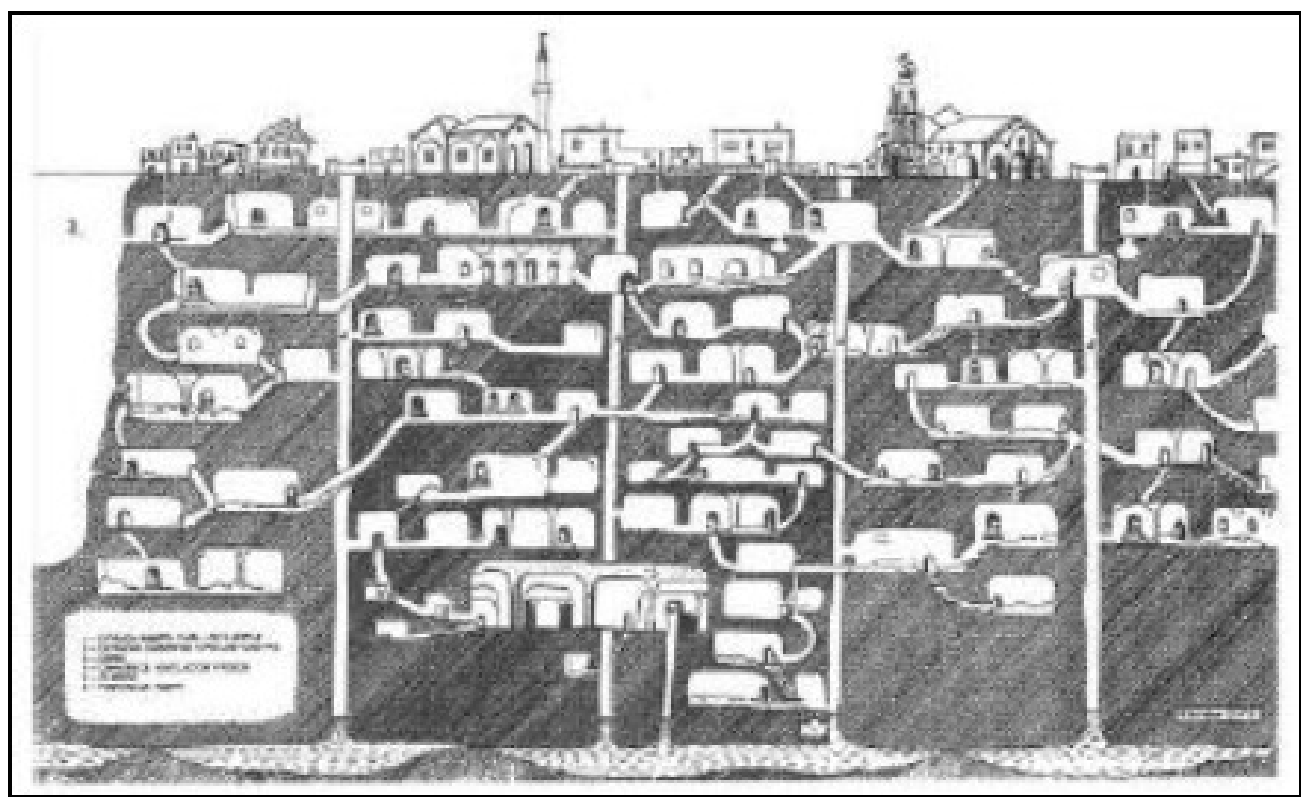

Fuente: Neila, 2004, p. 82

\section{Figura 7. Sección vertical de la ciudad subterránea de Derinkuyu}

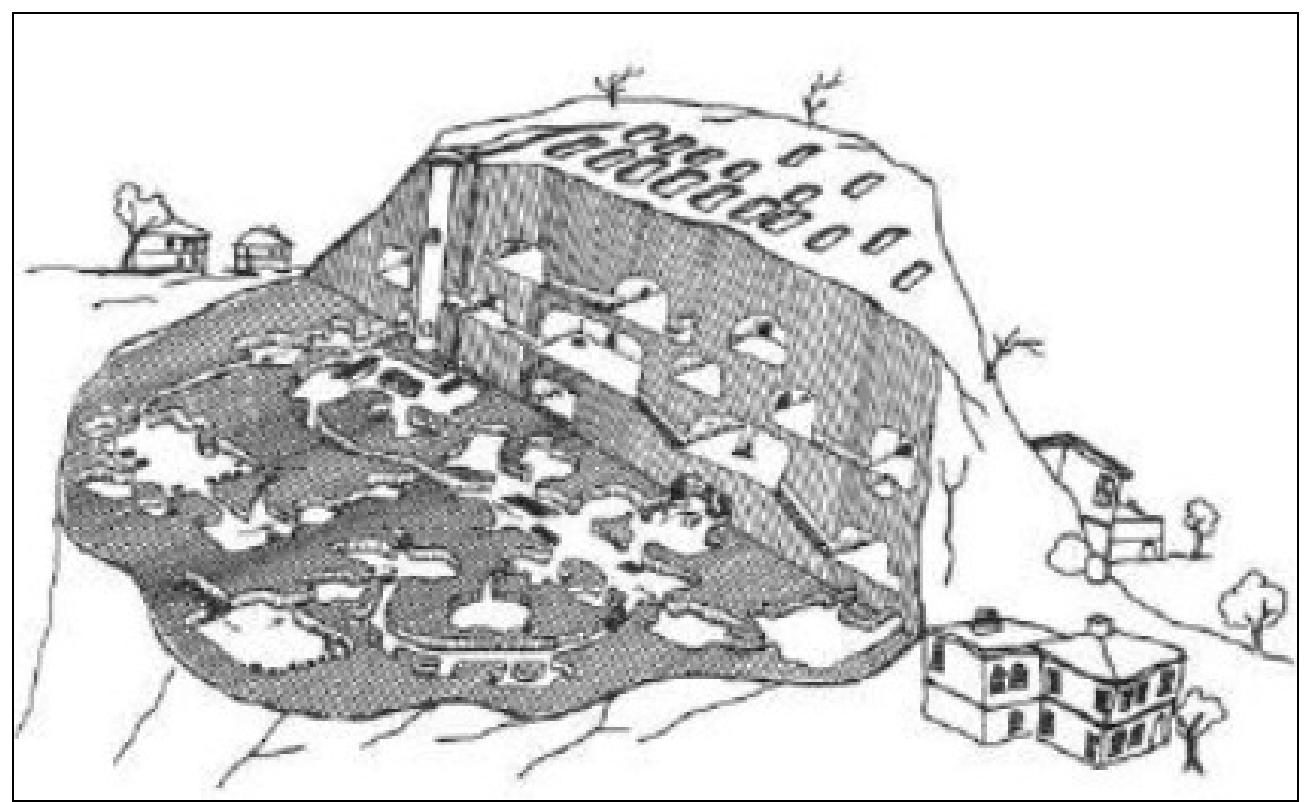

Fuente: Neila, 2004, p. 82.

Por último, hay que citar el origen defensivo del conjunto troglodítico de Matmata (Túnez). $\mathrm{Su}$ objetivo fundacional fue la defensa frente a los invasores, a través de comunidades interconectadas excavadas bajo las llanuras desérticas. La intención era confundirse con el entorno para pasar desapercibidas gracias al enterramiento. De hecho constituyen el último refugio de las tribus bereberes del norte de África frente a los musulmanes desde hace más de trece siglos (Neila, 2004). 


\section{Adaptación Económica}

Según Urdiales (2003:2), "la razón de la extensión de esta forma de vivienda está relacionada con la facilidad de su construcción, los bajos costes que requiere y la isotermia que dichas viviendas son capaces de mantener(...)". Estas razones valen tanto para España como para China, donde las cuevas se convierten en el refugio de los jornaleros y campesinos de escasos recursos. Por ello, el origen en la elección de este tipo de hábitat responde a las condiciones económicas de sus pobladores, como se desprende del análisis histórico para el caso de España. Según Urdiales (2003), las provincias con más población troglodita en 1987 eran Granada, Murcia y Alicante, por este orden. Esta distribución permite identificar que la distribución de cuevas en España se localiza en el sureste peninsular, que pudo actuar como foco irradiador de la cultura troglodita (García y López, 2000).

Las razones de esta concentración geográfica son por un lado físicas, ya que se localizan en la región peninsular de precipitación media anual más baja y de temperaturas máximas. Pero este emplazamiento también se explica por circunstancias históricas que apelan, en última instancia, a razones económicas. Como arquitectura popular, las viviendas subterráneas fueron exportadas desde el Magreb por los Almohades durante la Baja Edad Media. A esta conclusión apuntan evidencias extraídas de algunos estudios acerca de las casas-cueva de Guadix, uno de los asentamientos más numeroso de la Península Ibérica, que señalan la ausencia de esta tipología edificatoria antes del siglo XI (Urdiales, 1987). Esto coincide con la teoría de la tradición troglodita del norte de África que se remonta, al menos, a la Edad Antigua, cuando los romanos caracterizaban a los habitantes del Magreb por vivir en cuevas. La localización de una mayor densidad de casas-cueva, al menos durante el siglo XX, en el sureste peninsular coincide con las antiguas áreas de los reinos históricos de Granada y Murcia, solares de los imperios norteafricanos que revitalizaron Al-Andalus (Urdiales, 1987). Estos reinos se mantuvieron como reductos especialmente vinculados con el Magreb hasta el fin de la ocupación musulmana en la Península, a finales del siglo XV. Justamente es en este siglo y en Andalucía donde comienza a haber referencias de cuevas habitadas. En la extensión de este tipo de hábitat tuvo una influencia especial la expulsión de los moriscos del reino de Granada, producida en el último tercio del siglo XVI. A principios del siglo XVII la vuelta de una población morisca fugitiva y empobrecida provocó un aumento del número de casascueva en comarcas del sureste, como Guadix (Granada).

Durante el siglo XIX la situación de recuperación demográfica provoca una gran expansión agrícola, tras unas intensas roturaciones consecuencia de la desamortización de Mendizábal (1836) y Madoz (1855). Esto inicia una cadena de movimientos migratorios fruto de las transformaciones de las estructuras agrarias que supusieron la gran expansión de la vivienda subterránea. Los jornaleros se concentraban en las afueras de los núcleos urbanos, donde no había casas, tiempo o dinero para edificarlas, por lo que las cuevas se imponían como la única solución que, además, les ofrecían una protección contra el frío excelente. Este crecimiento fue tal que, ya en el siglo XX, en Crevillente (Alicante) la población asentada en cuevas en 1910 era de 4.460 habitantes, el 44,61\%, mientras que la asentada en casas era de 5.537, el 55,39\% restante (García y López, 2000). Esta situación se prolongó hasta la mitad del siglo $\mathrm{XX}$ en España, cuando el cambio de la estructura económica provoca un trasvase de población del sector primario al secundario y terciario, produciendo el éxodo rural. El abandono del mundo rural disminuye la presión demográfica y la demanda de vivienda, por lo que poco a poco se van abandonando las viviendas subterráneas, relacionadas por la población local como propias de situaciones de marginalidad y pobreza extrema, y se van sustituyendo por las actuales viviendas. Aun así mucha población siguió habitando casascueva, y se siguieron manteniendo las mismas características socioeconómicas. En la 
provincia de Granada en 1970, según el censo del Instituto Nacional de Estadística, el 85,8\% de la población que vivía en cuevas se empleaba en la agricultura, y de ellos el $75 \%$ lo hacía como trabajador eventual. Además nueve de cada diez viviendas analizadas carecían de servicios como agua corriente, retrete, cuarto de aseo o teléfono (Urdiales, 1979).

La situación de las viviendas subterráneas a lo largo de las últimas décadas del siglo XX y hasta la actualidad ha cambiado sustancialmente. A pesar de una disminución considerable del número de viviendas, al menos en España, las existentes se han acondicionado con los servicios básicos ya que ahora estas viviendas se perciben positivamente por parte de la población y existen políticas públicas orientadas a ese fin, cuyas inversiones son complementadas con las de la iniciativa privada. El reacondicionamiento de la cueva refleja el cambio de mentalidad de la población, que ahora concibe la vivienda subterránea como parte del patrimonio arquitectónico y residencial de sus municipios. Esta nueva concepción ha incrementado la demanda de este tipo de viviendas para uso como vivienda principal o secundaria, ya que junto a su condición de patrimonio histórico-residencial influye en su valoración su condición de vivienda bioclimática. Así pues, en las últimas décadas la concepción de las viviendas subterráneas como infraviviendas ha cambiado hasta el punto de que en la actualidad son un recurso turístico promovido desde la óptica del desarrollo rural y local y de la puesta en valor del patrimonio arquitectónico, cultural y paisajístico.

\section{LAS VIVIENDAS SUBTERRÁNEAS Y LOS RIESGOS NATURALES}

Como hemos analizado, las casas-cueva se distribuyen por todo el mundo albergando en algunas regiones a una población numerosa que es altamente vulnerable, por su condición socioeconómica y la posibilidad del derrumbamiento de la cueva, ante la ocurrencia de un eventual riesgo natural. A pesar de ello no hay publicaciones que traten el estudio de las casas-cueva desde la perspectiva del riesgo. Hay que tener en cuenta que las viviendas subterráneas se caracterizan por excavarse sin necesidad de establecer medios de contención y por suponer una creación colectiva, lo que ya de por sí constituye un factor de vulnerabilidad ante un riesgo natural, ya que la transferencia de conocimiento sobre la que se sustenta su construcción puede resultar inadecuada en algunos casos, ya que está basada en un proceso de prueba y error permanentemente corregible y adaptable. Así pueden producirse casos como el de Cuevas de Almanzora del 14 de Octubre de 2011, cuando un desprendimiento de un talud de arena arcillosa de entre 15 y 20 metros sepultó varias viviendas subterráneas, provocando el fallecimiento de tres personas (Fotografía 5). En este caso no fue necesaria la intervención de elementos externos (como lluvias intensas o sacudidas sísmicas), ya que la construcción de viviendas subterráneas sobre materiales poco consolidados, como la arena, no garantiza su estabilidad. 


\section{Fotografía 5. Desprendimiento en la zona conocida como cuevas del Castillo, en el barrio de EI Realejo, en Cuevas de Almanzora (Almería) el 14/10/2011}

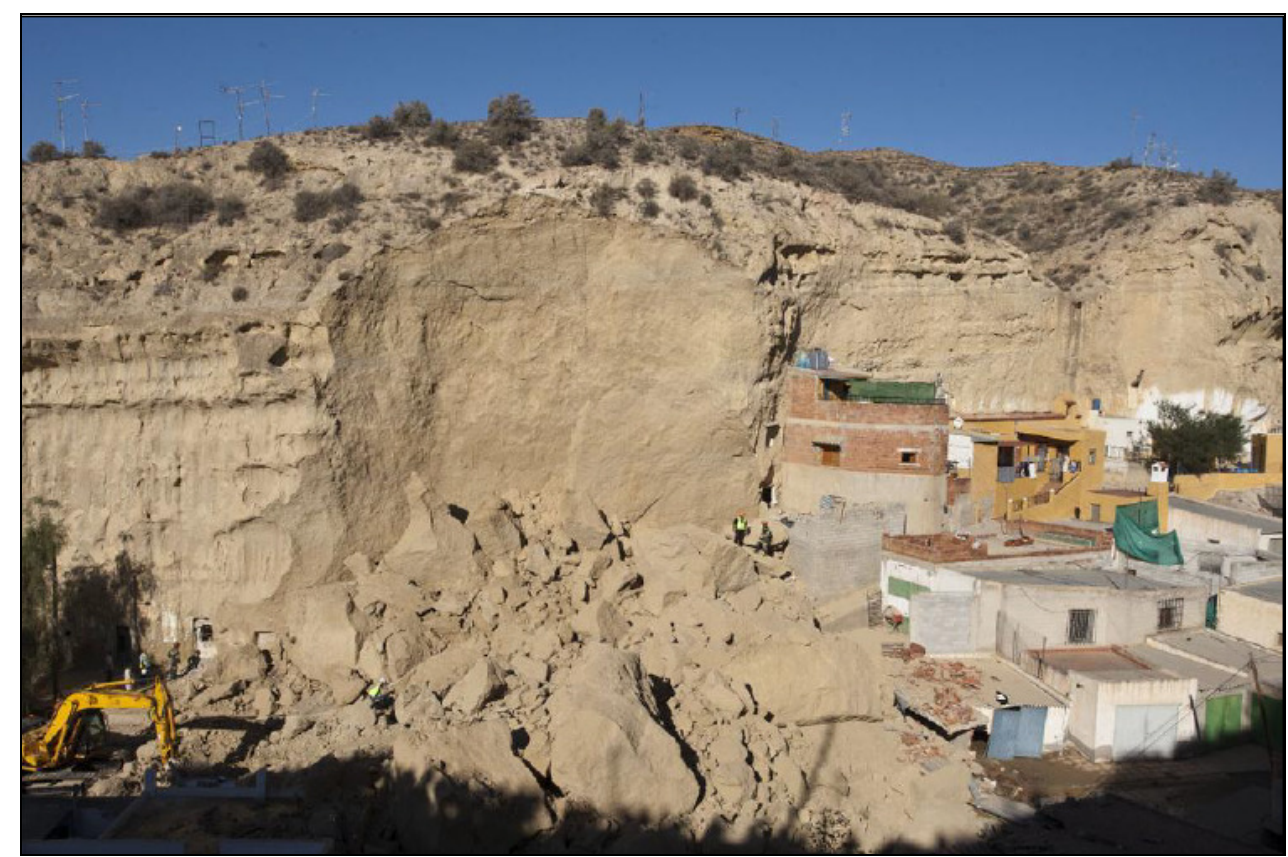

Fuente: <http://www.cosasdebomberos.es/images/stories/Derrumbamiento_Almeria.jpg >.

Esa incertidumbre en lo que se refiere a la estabilidad y mantenimiento de la cueva puede manifestarse de manera súbita, como consecuencia de un evento natural intenso, o paulatinamente a través de diferentes signos que se pueden percibir, como la aparición de grietas o el aumento de la humedad en el interior de la cueva que, en último caso, propiciará un derrumbamiento de la misma por pérdida de estabilidad. Habitualmente sobrevienen a la vez, ya que la aparición de grietas se suelen relacionar con los movimientos del terreno sobreyacente, generado en muchas ocasiones por aportes hídricos que aumentan su peso. También pueden aparecer las grietas o la humedad como consecuencia de la influencia antrópica. En el caso de las grietas, éstas pueden ser indicadores de un riesgo potencial, ya que las vibraciones resultado del paso de vehículos en carreteras o caminos situados sobre casas-cueva pueden llegar a provocar su derrumbamiento total o parcial. La aparición de humedad en la cueva puede deberse a diversas causas: fugas en tuberías de agua; falta de transpiración del terreno; subidas del nivel freático durante episodios de precipitaciones intensas, ya que muchas cuevas se sitúan en las vaguadas de las ramblas donde sube y baja súbitamente el nivel freático; filtraciones producidas por el agua de lluvia que aprovecha las grietas y diaclasas del propio terreno. Además, conforme menos ventiladas se encuentren las casas-cueva más aumentará la humedad, lo que resultará perjudicial tanto para su perdurabilidad como para la salud de sus habitantes ya que entre las causas que propiciaron su progresivo abandono en los años 50 en España se encontraba el desarrollo de enfermedades que diezmaron a su población, como las fiebres tifoideas y a la aparición de procesos de tipo tuberculoso, resultado de las condiciones de falta de ventilación y el alto grado de humedad.

Junto a las grietas y el grado de humedad de la cueva, manifestaciones paulatinas de un posible hundimiento, hay que tener en cuenta que las diferentes tipologías de cuevas presentan diferente vulnerabilidad ante un mismo peligro natural. Como ejemplo, tenemos el caso del ya mencionado conjunto de cuevas de Matmata (Túnez), de tipología mixta. En 1967 un temporal de lluvia torrencial que duró 22 días, un acontecimiento inusual en el Desierto del 
Sáhara para el que esta tipología no está adaptada, anegó estas excavaciones dándolas a conocer al mundo occidental que hasta entonces ignoraba su existencia. El carácter torrencial de las lluvias frecuente en los climas donde se dan las condiciones naturales para el establecimiento de viviendas subterráneas es uno de los factores que hay que tener en cuenta a la hora de estudiar el riesgo en estas viviendas. Este factor pluviométrico, unido a la presencia de materiales blandos y desprovistos de vegetación, facilita la erosión y, por tanto, la posibilidad de que se produzca un desprendimiento y la destrucción de la cueva (Urdiales, 1979). Otro factor que influye en la vulnerabilidad de las casas-cueva y de sus pobladores es el material sobre el que se encuentra excavada. Si se realiza sobre un terreno con gran porcentaje de arcilla, u otro material poco cohesionado, y éste posee un alto grado de humectación, la cueva pierde consistencia y se puede producir su derrumbamiento. Aunque normalmente la posibilidad de hundimiento de la vivienda va desapareciendo con el paso del tiempo, ya que este material se endurece mucho al cabo de los años, sobre todo si en el terreno hay intercalaciones de conglomerados o areniscas.

\section{Viviendas subterráneas y riesgo sísmico}

La distribución del hábitat de viviendas subterráneas se localiza, en muchas ocasiones, en áreas activas sísmicamente. El caso de España es una muestra de ello, puesto que la mayor densidad de población troglodita la encontramos en el sureste peninsular, que es precisamente donde hay una mayor actividad sísmica (Figura 8). La coincidencia de la localización de casas-cueva junto a áreas de actividad sísmica hace necesario el estudio de las interacciones entre los terremotos y las viviendas subterráneas.

Las consecuencias que un movimiento sísmico puede provocar sobre una casa-cueva dependen de la naturaleza del suelo y la disposición sobre la que se instala la cueva. En función de estas características pueden observarse distintas respuestas, como pueden ser los fenómenos de amplificación de la señal de las ondas sísmicas en suelos de materiales sueltos o procesos de licuefacción en el caso de suelos saturados de agua. En el caso de que el suelo esté compuesto por roca homogénea la amplificación de las ondas será mucho menor. Así pues, el tipo de materiales y su disposición son quienes pueden jugar un papel determinante en la amplificación de una señal sísmica y, por tanto, afectar más o menos a la estabilidad de una casa-cueva. Según Giner y Molina (2001, p. 93), las propiedades mecánicas de determinados materiales en los que se está propagando la onda sísmica hacen que ésta quede atrapada en su seno. "Esto hace que los estratos, o conjunto de capas que forman dicho material entren en resonancia amplificándose determinadas frecuencias. Este fenómeno suele darse más fácilmente cuando el material está saturado en agua, tiene baja densidad y se encuentra en estado de baja compactación. Si además, las capas que hay bajo este material tienen propiedades muy diferentes de las de él, el efecto se ve favorecido aún más" (Giner y Molina 2001, p. 93). 


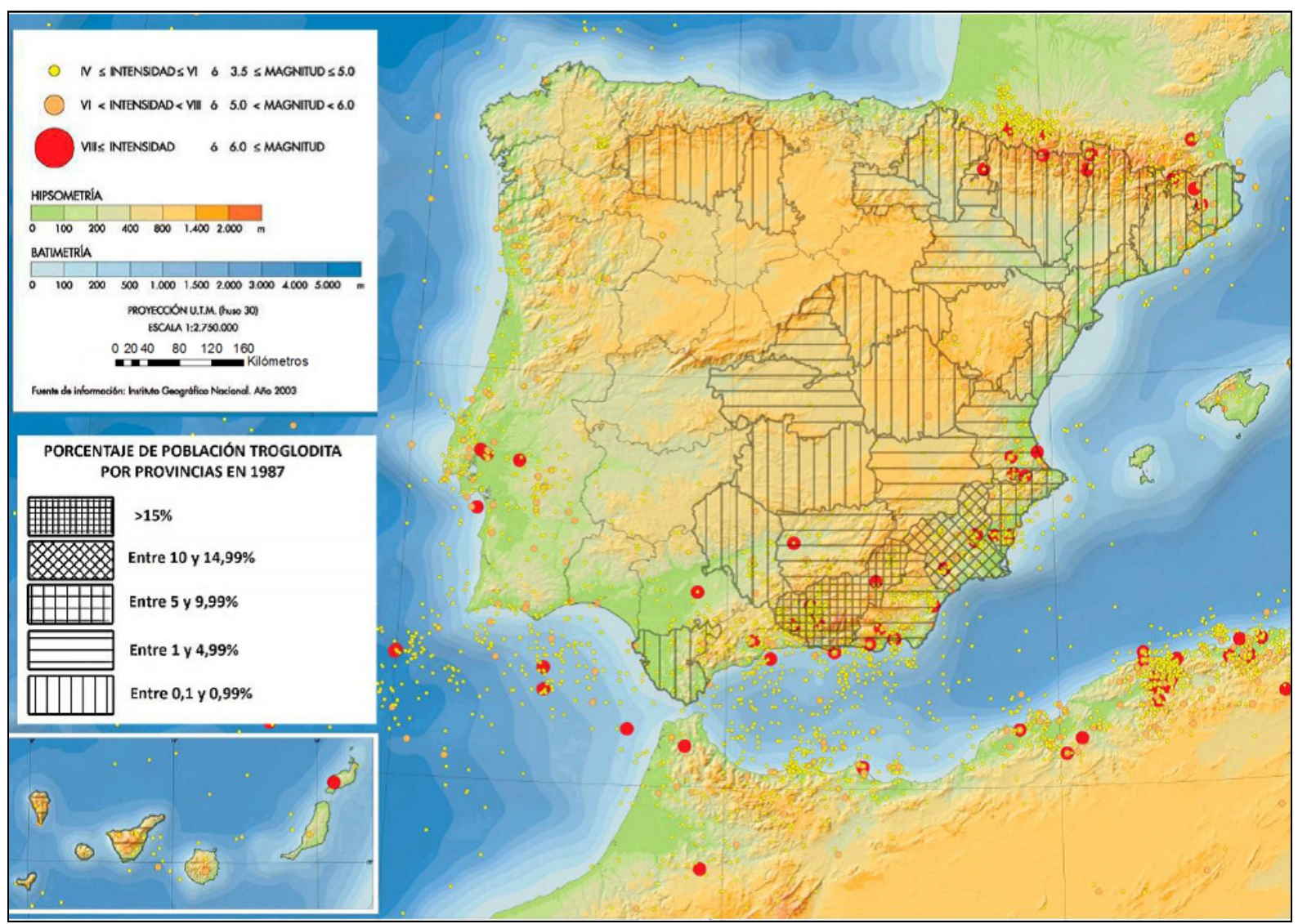

Fuente: Elaboración propia a partir del Mapa de Sismicidad del Atlas Nacional de España y de Urdiales, 1984.

Por otro lado, no sólo las cuencas cerradas o los relieves topográficos favorecen la amplificación de la señal sísmica. Los valles de los ríos actúan también como excelentes amplificadores de las señales sísmicas. Esto se debe a que las características mecánicas de los materiales que allí se depositan son mucho más bajas que las de los materiales subyacentes, por lo que el contraste entre ellos es mayor. Y si además tenemos en cuenta que el material se encuentra saturado en agua y tiene poca densidad y compactación, el resultado es que los valles de los ríos constituyen un territorio de elevado riesgo sísmico. Esta amplificación de la señal sísmica ocurrió en el fatídico terremoto de Torrevieja (Alicante), ocurrido el 21 de marzo de 1829, en el que murieron unas 400 personas y se derrumbaron muchos edificios de las ciudades de la comarca del Bajo Segura. La intensidad del terremoto, que fue de grado X según la escala de Mercalli Modificada, se vio incrementada debido a la existencia de materiales aluviales y al elevado nivel freático, que amplificaron la señal sísmica. Hay estudios detallados que abordan el nuevo urbanismo adaptado a las condiciones sísmicas que se llevó a cabo en el Bajo Segura a raíz de esta catástrofe (Canales, 1984), pero no hay información acerca de las posibles repercusiones que tuvo el terremoto sobre las casas-cueva que presumiblemente podían encontrarse en las sierras de la comarca como las de Escalona, Orihuela o Callosa. Hay que tener en cuenta que la tipología horizontal característica de este área se da sobre laderas, lo que disminuye la propagación de ondas sísmicas, y litológicamente se da en materiales calcáreos, por lo que la vulnerabilidad ante el riesgo 
sísmico en este tipo de viviendas es menor, y puede que por ello no haya noticias sobre los efectos del terremoto sobre las viviendas subterráneas del entorno.

Pero no sólo se localizan casas-cueva en zonas sísmicas ibéricas, ya que existen numerosos ejemplos. Uno de ellos lo supone la necrópolis rocosa de Pantalica en Sicilia (Italia), que se encuentra excavada en roca caliza (Fotografía 6). Fue construida hace unos 3.000 años en las laderas verticales del valle de Anapo con una tipología horizontal, que ha resistido los numerosos eventos sísmicos registrados en la isla presumiblemente por el tipo de roca y la disposición de la cueva. Además de esta necrópolis encontramos más ejemplos en Italia, en concreto en la isla de Sicilia, que experimenta una gran actividad sísmica y volcánica, donde se han desarrollado una gran variedad de asentamientos trogloditas.

\section{Fotografía 6. Necrópolis rocosa de Pantalica, Sicilia}

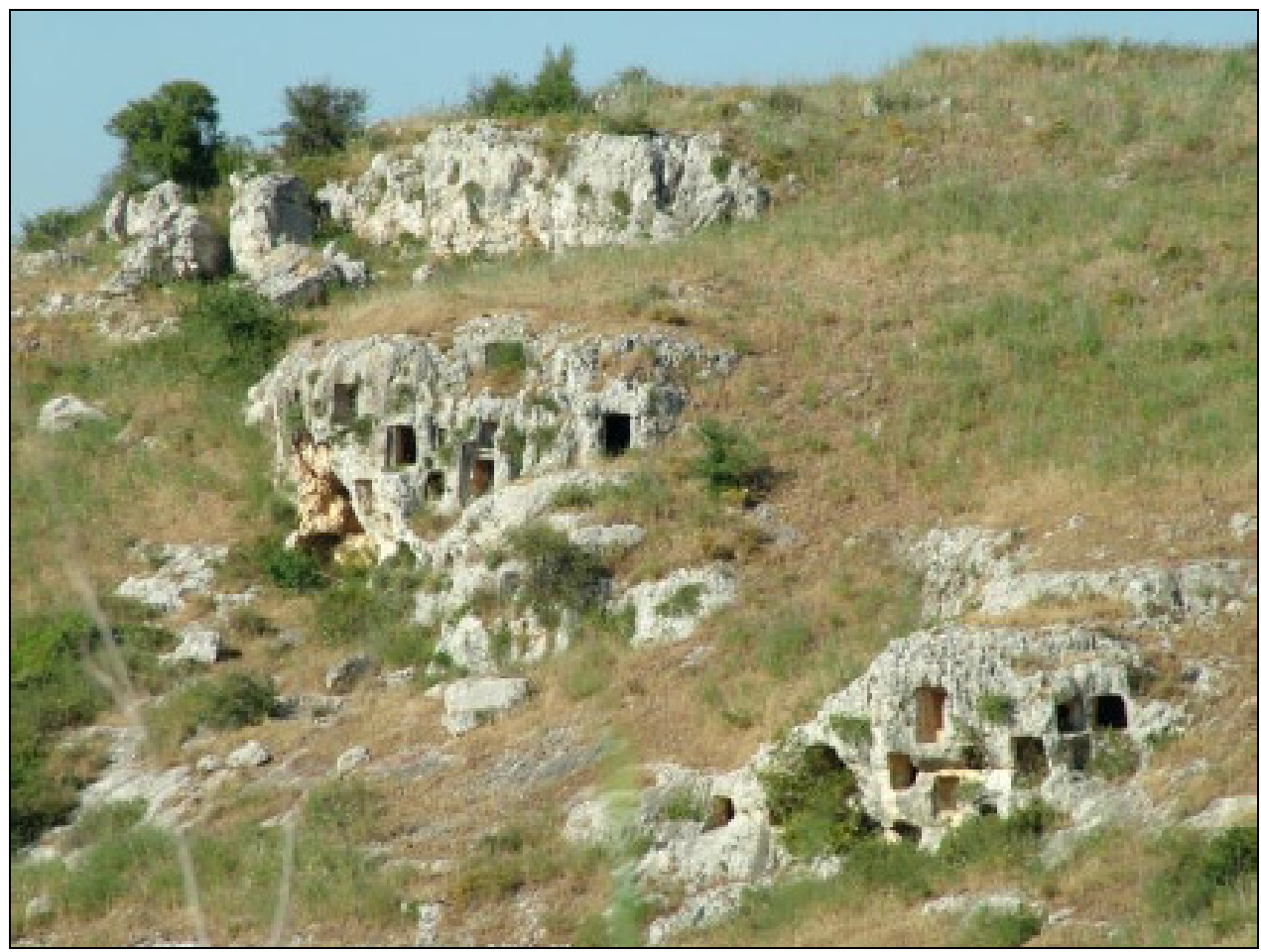

Fuente: $<$ http://upload.wikimedia.org/wikipedia/commons/2/24/Nekropolis_von_Pantali ca.jpg $>$.

Por otro lado, en la región de Capadocia (Turquía) los pináculos formados por toba volcánica han sido endurecidos por el contacto con el aire, formando un enclave troglodita en una región de gran actividad sísmica que ha perdurado desde hace siglos hasta la actualidad. En esta región encontramos, además, otras tipologías de vivienda subterránea, como comentamos anteriormente, que se desarrollaron formando auténticas ciudades subterráneas construidas sobre loess, que se trata de materiales blandos poco asentados que en caso de un fuerte terremoto podrían llegar a colapsar. De hecho, muchos autores citan que en esta región de Turquía debe haber unas 30 ciudades subterráneas (Piedecausa, 2012), según testimonios escritos, aunque podría ser que alguna hubiera colapsado debido a la combinación de las características litológicas y las condiciones sísmicas de la región.

Esto ocurrió en el año 1556 en la provincia China de Shaanxi, situada al norte del país, donde la proliferación de casas-cueva desde hace siglos en un espacio con una gran actividad 
sísmica desencadenó el desastre natural que más víctimas ha causado por movimiento sísmico del que se tienen registros.

\section{El desastre de Shaanxi}

En el norte de China encontramos la región de loess más importante del mundo, la Meseta de Loess o meseta de Huangtu, un altiplano formando durante millones de años debido a la deposición por el viento de este material traído desde el Desierto de Gobi. La meseta cubre un área de unos $640.000 \mathrm{~km}^{2}$ en el curso alto y medio del río Amarillo o Huang He. Es una región de suelo limoso muy propenso a la erosión tanto eólica como hídrica, puesto tiene una alta porosidad, del $45 \%$ aproximadamente. Esta región se caracteriza climáticamente, por tener unas precipitaciones inferiores a los $600 \mathrm{~mm}$ anuales de media en las zonas más húmedas y meridionales. Además en cuanto a las temperaturas, existe una gran amplitud térmica diaria (de más de $20^{\circ} \mathrm{C}$ ) y estacional, presentando así, junto con la facilidad de excavación del loess, todas las condiciones para la excavación de casas-cueva de tipología mixta, que en esta región son conocidas como yaodongs (que significa "cueva horno"), aprovechando así el alto poder aislante del loess frente a los fríos inviernos y los calurosos veranos de la zona (Figura 9).

En esta región el poblamiento es esencialmente rural, vinculado a una economía agraria que se aprovecha de la fertilidad del suelo, y encontró hace siglos en esta opción urbanística una solución económica a los problemas de hábitat, que además se adaptaba a la necesidad de dejar libre la superficie para los cultivos. Por todas estas razones en la actualidad se siguen habitando estas cuevas, aunque los cientos de años de deforestación y sobreexplotación ganadera debidos al incremento de la población china han dado lugar a la degeneración de los ecosistemas y a un alto grado de desertización, empobreciéndose así las economías de la zona. En la actualidad se estima que siguen viviendo unos 30 millones de personas en yaodongs en China. Hacia finales del siglo XVI, se produjo un gran terremoto en la región, lo que provocó el derrumbe de innumerables yaodongs por un gran número de deslizamientos de tierra.

Es el terremoto que más muertes ha provocado en la historia, de los que hay registros documentales, y el quinto desastre natural más mortífero, aunque muchos terremotos hasta la fecha han tenido magnitudes mayores. El epicentro se localizó en la localidad de Huaxian, provincia de Shaanxi, a unos 80 kilómetros noreste-este de la ciudad de Xi'an. Se produce en la mañana del 23 de enero de 1556 estimándose su magnitud en 8,0 en la escala Richter y su intensidad en XI según la escala de Mercalli Modificada. El terremoto fue especialmente destructivo en la provincia de Shaanxi, pero fue responsable de la devastación de 98 condados y ocho provincias en el centro de China (Figura 10). Sus efectos se dejaron notar hasta en la provincia de Hunan, a más de 800 kilómetros de distancia. Produjo fisuras en el suelo, levantamientos, hundimientos, fenómenos de licuefacción y deslizamientos de tierra. 
Figura 9. Sección por el acceso y perspectiva de conjunto de un yaodang

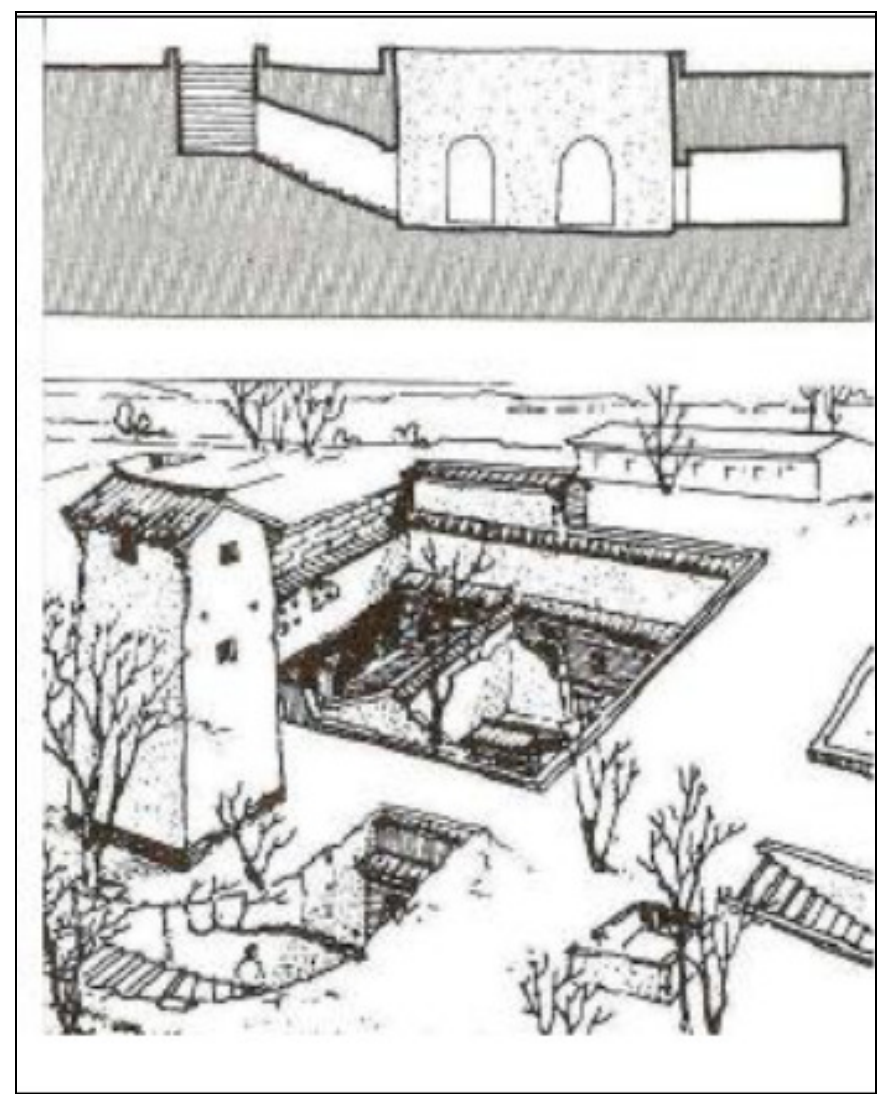

Fuente: Loubes, 1985, p. 76.

En los anales de China (VV.AA, 1981:100) fue descrito como:

“(...)En el invierno de 1556, un terremoto catastrófico ocurrió en las provincias de Shanxi y Shaanxi. En nuestro Condado de Hua, varias desgracias tuvieron lugar. Montañas y ríos cambiaron de lugar y carreteras fueron destruidas. En algunos lugares el suelo de repente se elevó y formó nuevas colinas, o se hundió abruptamente y llegó a formar nuevos valles. En otras áreas, el flujo estalló en un instante, el suelo se rompió y aparecieron nuevos barrancos. Cabañas, casas oficiales, templos y los muros de la ciudad colapsaron instantáneamente...”.

En algunos condados el número promedio de las muertes que supuso este terremoto se estimaron en torno al $60 \%$ de la población. En total y según los registros históricos, más de 830.000 personas perdieron la vida. La mayoría de estas víctimas fueron consecuencia de la caída de casas deficientemente construidas y por el colapso de los yaodongs. Este caso nos muestra la gravedad de los daños que puede causar la combinación de un peligro, como es un evento sísmico de gran potencia, junto con una situación de vulnerabilidad bastante alta representada por este tipo de casas-cueva. Al estar construidas en superficies llanas sobre un terreno de loess con un nivel freático presumiblemente bajo, dado el carácter predominantemente agrícola de la zona, se potenciaron los efectos destructivos de las ondas sísmicas. La vulnerabilidad ante este fenómeno natural, por tanto, fue aumentada por la tipología y por el material constituyente de las cuevas. 


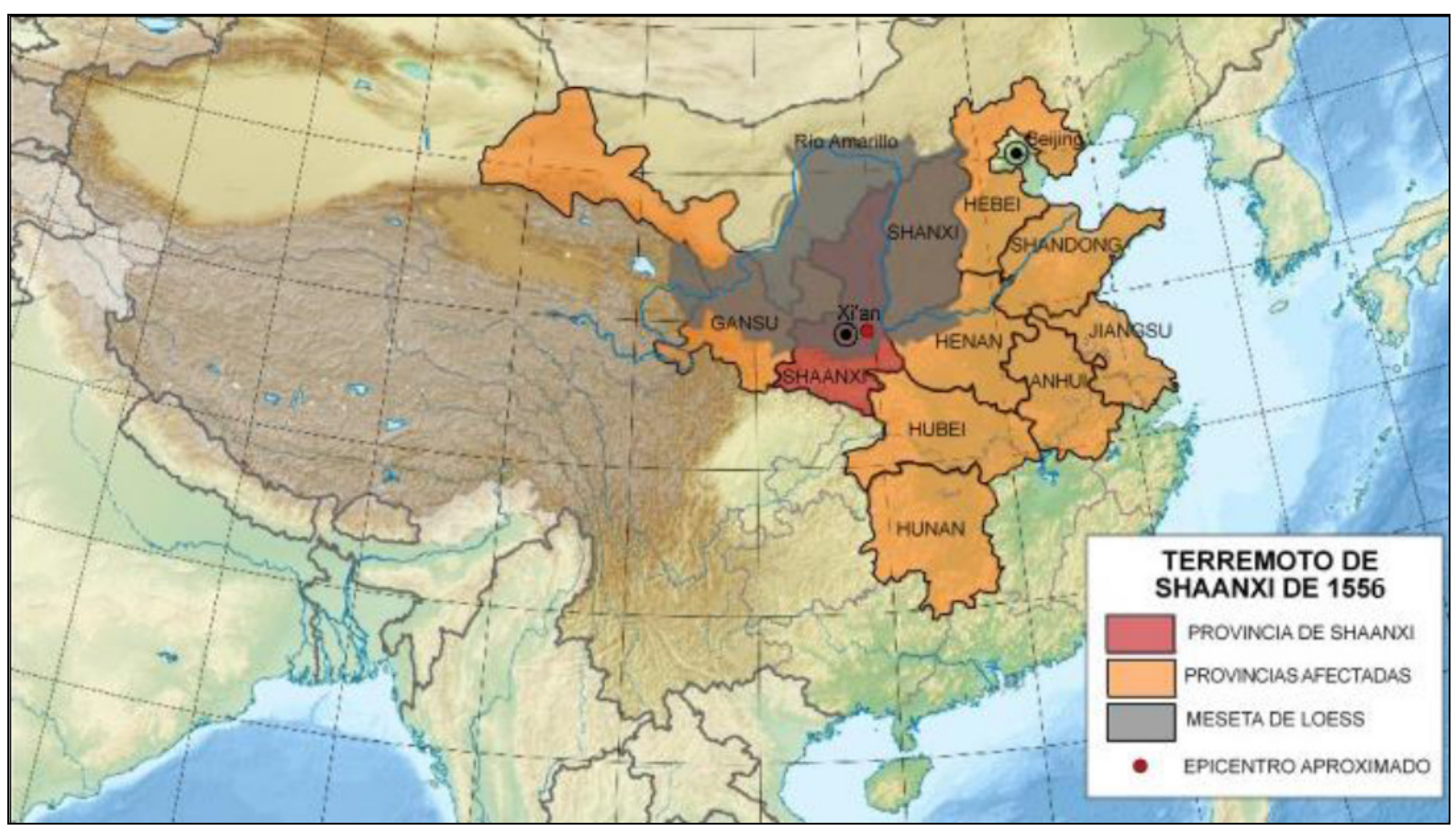

Fuente: Elaboración propia.

\section{CONCLUSIONES}

La casa-cueva es el resultado de la interacción del ser humano con el medio físico para satisfacer su necesidad de cobijo, en la mayoría de los casos con fines defensivos o motivado por una escasez de medios económicos. En la actualidad el hábitat resultante de estas estrategias adaptativas es concebido como un patrimonio histórico, cultural, arquitectónico y paisajístico que está siendo puesto en valor y que complementa otros activos territoriales que pueden ser aprovechados desde la óptica del desarrollo local. A pesar de la disminución del poblamiento en este tipo de hábitat a lo largo de todo el mundo, las casas-cueva están siendo consideradas como un modelo de vivienda ecológica de futuro dadas sus ventajas en cuanto a eficiencia térmica.

Pero para este posible desarrollo es necesario alcanzar un mejor conocimiento de las interacciones entre la actividad sísmica y la vivienda subterránea a escala local, estudiando las particularidades de cada territorio, de cara a garantizar unas condiciones mínimas de seguridad frente a posibles movimientos sísmicos así como para mantener el patrimonio que suponen estas viviendas y permitir su puesta en valor. Hay que tener en cuenta que gran parte de la población que sigue habitando viviendas subterráneas a lo largo del mundo sigue siendo muy vulnerable a los riesgos naturales como el que ocurrió hace siglos en Shaanxi. Este desastre natural no supuso el fin del poblamiento chino en casas-cueva, ya que millones de personas siguen viviendo en yaodongs. A pesar de los riesgos que presenta este hábitat en esa región las condiciones socioeconómicas imponen a sus residentes el tipo de vivienda en la que desarrollan su vida, por lo que hay probabilidad de que se repita lo ocurrido en 1556. 


\section{BIBLIOGRAFÍA}

ARANDA, F. Materia prima. Arquitectura subterránea excavada en Levante. Valencia: Ediciones Generales de la Construcción, 2003. 143 p.

CANALES, G. El nuevo urbanismo del Bajo Segura a consecuencia del terremoto de 1829 . Investigaciones Geográficas,. 1984, nº 2, p. 149-172.

CARMONA, D. La conformación del patrimonio etnológico. Tradición cultural y etnocentrismo en el caso de las casas-cueva. Revista de la Facultad de Ciencias Sociales y Jurídicas de Elche, 2006, vol. I, nº 1, p. 270-290.

DEFFONTAINES, P. L'homme et sa maison. Collection Géographie Humaine. Mayenne: Éditions Gallimard, 1980. 256 p.

ELNADI, B. El mundo de los trogloditas. Organización de las Naciones Unidas para la Educación, la Ciencia y la Cultura. Francia. El Correo de la Unesco, 1995, diciembre, p. 1022.

FERNÁNDEZ, E. Agua y vida en Cuevas de Almanzora. Una historia de luchas y anhelos (Siglos XVI-XXI) Mojácar: Arráez Editores, 2006. 336 p.

GARCIA, J. A. y LÓPEZ, J. A. Las cuevas de Crevillent: estudio y catálogo gráfico. Alicante: Instituto Alicantino de Cultura "Juan Gil-Albert", 2000. 174 p.

GINER, J. y MOLINA, S. Sismicidad y riesgo sísmico en la C.A.V. San Vicente del Raspeig: Editorial Club Universitario, 2001.108 p.

GONZALO, G. E. Manual de Arquitectura Bioclimática. Buenos Aires: Nobuko, 2003. 470 p.

GSELL, S. Histoire ancienne de l'Afrique du Nord. Hachette: Paris, 1913. 544 p.

JESSEN, O. Las viviendas trogloditas en los países mediterráneos. Estudios Geográficos, 1955, p. 137-157.

LOUBES, J. P. Arquitectura subterránea. Aproximación a un hábitat natural. Barcelona: Gustavo Pili, 1985.127 p.

MACCARONE, A. El paisaje de las cuevas en Molise en comparación con otras regiones mediterráneas. Propuestas para su catalogación y protección. Tesis doctoral dirigida por Donatella Cialdea. Campobasso, Universitá degli studi del Molise, 2009.

NEILA, F. J. Arquitectura bioclimática en un entorno sostenible. Madrid: Munilla-Lería. 2004. $440 \mathrm{p}$.

OMEDES, A. y PIQUÉ, J. Los otros arquitectos. Barcelona: Gustavo Pili, 2003. 151 p.

PIEDECAUSA, B. La vivienda tradicional excavada: Las casas-cueva de Crevillente. Análisis tipológico y medidas de calidad del aire. Tesis doctoral dirigida por Servando Chinchón Yepes. San Vicente del Raspeig, Universidad de Alicante, 2012. 
URDIALES, M. E. Algunos aspectos del hábitat troglodita en la provincia de Granada. Cuadernos Geográficos de la Universidad de Granada, 1979, nº 9, p. 311-338.

URDIALES, M. E. La cueva como vivienda. Forma de expresión de la arquitectura popular adaptada al medio geográfico. Cuadernos Geográficos de la Universidad de Granada, 1984, $n^{\circ} 14$, p. 85-100.

URDIALES, M. E. Cuevas de Andalucía: evolución, situación y análisis demográfico en la provincia de Granada. Granada: Conserjería de Obras Públicas y Transportes, 1987. 818 p.

URDIALES, M. E. Las cuevas-vivienda en Andalucía: de infravivienda a vivienda de futuro. Universidad de Granada. Scripta Nova, Revista Electrónica de Geografía y Ciencias Sociales, 2003, vol. VII, nº 146 (051).

MARÍN, B. Cuevas en la provincia de Granada. Aspectos técnicos, urbanísticos, legales, patrimoniales y perspectivas para el desarrollo local de la provincia. Granada: Diputación Provincial de Granada. Proyecto Eurocuevas, 2010. p.166 p.

VV. AA. 30 years review of China's Science \& Techonology, 1949-1979. Singapur: World Scientific, $1981.313 \mathrm{p}$.

(C) Copyright Rubén Villar Navascués y Revista GeoGraphos, 2016. Este artículo se distribuye bajo una Licencia Creative Commons Reconocimiento-NoComercial 4.0 Internacional.

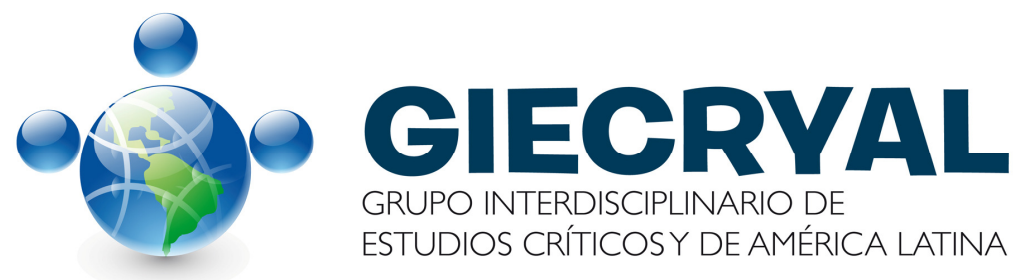

